\title{
Mapping of Quantitative Trait Loci Controlling Seedling Growth in Bunching Onion (Allium fistulosum L.)
}

\author{
Takayoshi Ohara*, Hikaru Tsukazaki, Yeon-Sang Song**, Tadayuki Wako, \\ Ken-ichiro Yamashita and Akio Kojima
}

National Institute of Vegetable and Tea Science, Kusawa, Ano, Tsu 514-2392, Japan

\begin{abstract}
Vigorous seedling growth is a desirable trait for machine-assisted transplanting using a plug nursery system in bunching onion. This study was undertaken to identify the quantitative trait loci (QTLs) controlling seedling growth and to elucidate the modes of gene action of the QTLs. Plant material was a set of reciprocally backcrossed populations $\left(\mathrm{BC}_{1}\right)$. These were produced from 2 inbred lines derived from the Senju group and Kujo group. Two corresponding $\mathrm{BC}_{1}$ maps were constructed by adding co-dominant simple sequence repeat (SSR) markers to the previously reported amplified fragment length polymorphism (AFLP) based maps. Fresh weights of seedlings were measured in 3 seasons using $\mathrm{BC}_{1} \mathrm{~S}_{1}$ families. Remarkable heterosis was observed in $\mathrm{F}_{1}$ and many $\mathrm{BC}_{1} \mathrm{~S}_{1}$ families. Many QTLs for seedling weight were detected on the 2 maps by composite interval mapping. The phenotypic variation explained by a single QTL was less than $25 \%$. Of these, 3 QTLs on 3 linkage groups are considered to be consistently effective across different environmental conditions because they were detected in different years and seasons. Most QTLs were detected on one map, but were not detected in a corresponding region on the other map; however, the degree of dominance at each locus was calculated to determine whether the locus shows overdominance. Overdominance was observed at some loci, and the other loci showed an additive and dominant effect. It is suggested that remarkable heterosis for seedling weight in the present population is based on the accumulation of dominant and overdominant gene actions.
\end{abstract}

Key Words: backcross, heterosis, overdominance, QTL, seedling growth.

\section{Introduction}

Bunching onion (Allium fistulosum L.) is an important vegetable crop with high annual output following tomato, strawberry, and cucumber in Japan (MAFF, Japan, 2008). Many local varieties have been adapted to various climatic conditions in Japan. They are classified into 4 groups according to their utilization and growing characteristics: Kaga, Senju, Kujo and Yagura-negi (Inden and Asahira, 1990). The cultivation of bunching onion requires transplantation of young seedlings. Traditionally, seedlings raised in a nursery bed are transplanted to the field by hand. Recently machine-

Received; March 23, 2009. Accepted; June 1, 2009.

This work was supported by the project "Green Technology Project (DM-1604)", Ministry of Agriculture, Forestry and Fisheries, Japan.

* Corresponding author (E-mail: tohara@affrc.go.jp).

** Present address: Mokpo Experimental Station, National Institute of Crop Science, 293-5 Cheongcheon, Cheonggye, Muan, Jeonnam 534-833, Korea. assisted transplanting technology using plug nursery systems has become common because this saves substantial labor during transplanting (Shiraiwa et al., 2006; Yokoyama, 1996). However, bunching onion grows very slowly in the initial growth phase. Moreover, the nursery period is limited because of the small soil volume in the plug system. Because very young and small seedlings must be transplanted to fields, unfavorable weather such as drought or heavy rain sometimes severely retards growth. Therefore, breeding cultivars showing vigorous growth in young seedling stages is anticipated.

In an earlier study, we examined the seedling growth of $F_{1}$ hybrids between various inbred lines or cultivars in bunching onion, and demonstrated that $\mathrm{F}_{1}$ between the Senju group and Kujo group showed remarkable heterosis in seedling growth (Ohara et al., 2004; Ohara et al., 2005b). The results suggest that the breeding of cultivars with vigorous seedling growth is possible using heterosis, and the resulting cultivar might be suitable for the plug nursery system and machine-assisted transplant- 
ing. Elucidation of the genetic nature of the heterosis is a prerequisite for this breeding. In maize, quantitative trait loci (QTL) analysis for yield or yield components have been conducted, with the results suggesting that overdominant gene action played a role in heterosis ( $\mathrm{Lu}$ et al., 2003; Stuber et al., 1992).

Genetic and molecular studies in bunching onion are not so advanced because of its severe inbreeding depression, long generation time, and huge genome size $\left(1.2 \times 10^{4} \mathrm{Mbp}\right.$, Ricroch et al., 2005). Recently, we developed simple sequence repeat (SSR) markers of bunching onion (Song et al., 2004), and constructed 2 linkage maps mainly based on amplified fragment length polymorphism (AFLP) markers using reciprocal backcrossed progenies (Ohara et al., 2005a).

For the present study, we identified QTLs controlling seedling growth using genetic maps and also attempted to elucidate whether these QTLs show overdominance using 2 backcrossed populations of bunching onion.

\section{Materials and Methods}

\section{Plant materials and collection of phenotypic data}

Mapping populations were the same as described by Ohara et al. (2005a). Two inbred lines-D1s-15s-22 (Senju group: D) and J1s-14s-20 (Kujo group: J)—were used as the parents. We previously reported that their $\mathrm{F}_{1}$ hybrid indicated remarkable heterosis, and showed excellent seedling growth compared with standard OP and $F_{1}$ cultivar (Ohara et al., 2004). A single plant of $\mathrm{F}_{1}$ was backcrossed to each of the parental lines to obtain a set of reciprocally backcrossed populations: (D) $\mathrm{BC}_{1}$ and $(\mathrm{J}) \mathrm{BC}_{1}$. For DNA marker analysis, 120 plants each of $\mathrm{BC}_{1}$ populations were used. These $\mathrm{BC}_{1}$ plants were self-pollinated individually to generate $\mathrm{BC}_{1} \mathrm{~S}_{1}$ families. For evaluation of seedling traits, $118-119$ (D) $\mathrm{BC}_{1} \mathrm{~S}_{1}$ families and 105-112 (J) $\mathrm{BC}_{1} \mathrm{~S}_{1}$ families were examined in 3 seasons: fall 2002, spring 2003, and spring 2004. The seeds were sown individually in a 200-cell plug tray filled with compost (Yanmar Yasai Youdo; Yanmar Co. Ltd., Osaka, Japan) and settled on an under-tray filled with another kind of compost (Kureha Engei Baido; Kureha Co., Tokyo, Japan). At the transplanting stage (7 weeks after sowing), the seedlings were removed from the trays and the roots were washed and pruned to a length of approximately $3 \mathrm{~cm}$. Then fresh weights were measured at the transplanting stage (FW1). These seedlings were transplanted to beds in a plastic house, and then fresh weights at 5 weeks after transplanting were measured as described above (FW2). For the fall sowing test in 2002, seeds were sown during September 13-25, and 5 plants per plot were examined with 10 replications. Similarly, for the spring sowing test in 2003, seeds were sown during March 12-14, and 10 plants per plot were evaluated with 5 replications. For the spring sowing test in 2004, seeds were sown on March 23-25, and 6 plants per plot were examined with 8 replications. We previously reported that seedling weight in the early growth stage is significantly correlated with seed weight (Ohara et al., 2004). The FW1 value was again positively correlated with seed weight in all 3 tests in this study $\left(r=0.28^{* *}-0.56^{* *}\right.$, significant at the $1 \%$ level). To eliminate the effect of seed weight, FW1 of each family was corrected using the following equation:

Corrected fresh weight $=$ observed fresh weight $+b$ (average seed weight-seed weight), where $b$ is the regression coefficient of fresh weight on seed weight. On the other hand, the FW2 value was not corrected because of poor correlation with the seed weight.

\section{Map construction and QTL analysis}

A genetic linkage map of $\mathrm{J}$ was constructed based on segregation in the (D) $\mathrm{BC}_{1}$ population. Similarly, a $\mathrm{D}$ map was constructed using the $(\mathrm{J}) \mathrm{BC}_{1}$ population. SSR markers newly reported by Tsukazaki et al. (2007) were mapped on previous maps (Ohara et al., 2005a). Linkage analysis was conducted using a computer program (MAPMAKER/EXP 3.0; Lander et al., 1987) with the Kosambi function (Kosambi, 1944). Subsequently, QTL analysis was performed with a computer program (QTL Cartographer ver. 2.5; Wang et al., 2007) using the composite interval mapping (CIM) method. The loglikelihood (LOD) threshold was determined with 1000 permutations $(P<0.05)$.

\section{Estimation of genetic effect on seedling growth}

Overdominance is a phenomenon by which the heterozygous genotype $(D J)$ is superior to both homozygous genotypes $(D D$ and $J J)$. At the overdominant locus, the dominant effect $(d)$ is greater than the additive effect $(a)$. Because the QTLs based on a single $\mathrm{BC}_{1}$ map only respectively donate $d-a$ or $a+d$, we used data at the 2 corresponding genomic regions of the 2 maps (Table 3). If a significant QTL was detected in one map, we used data for the point showing the highest LOD value in the other map within the confidence area of the QTL detected. The degree of dominance was computed as the absolute value of $d / a$. The dominance effect in the present $\mathrm{BC}_{1} \mathrm{~S}_{1}$ plants theoretically decreases to half the value in the $\mathrm{BC}_{1}$ generation; therefore, the obtained values for the dominance in $\mathrm{BC}_{1} \mathrm{~S}_{1}$ families were doubled and used as $d$.

\section{Results}

\section{Phenotypic traits}

The results of the 3 cultivations are presented in Table 1. The mean fresh weight of D was heavier than that of $\mathrm{J}$ in all 3 cultivations. The mean fresh weight of $\mathrm{F}_{1}$ was always higher than those of the parents, indicating strong heterosis over the mid-parent, as shown previously (Ohara et al., 2004). Significant differences were found among the means of $\mathrm{BC}_{1} \mathrm{~S}_{1}$ families. These were distributed continuously; numerous $\mathrm{BC}_{1} \mathrm{~S}_{1}$ families showed the same or greater weight than $F_{1}$. Means of backcrossed lines were lower than those of $\mathrm{F}_{1}$, but in 
Table 1. Seedling weight of parents, $\mathrm{F}_{1}$ and $\mathrm{BC}_{1} \mathrm{~S}_{1}$ families.

\begin{tabular}{|c|c|c|c|c|c|c|c|c|c|}
\hline \multirow{2}{*}{ Trait $^{2}$} & & \multirow{2}{*}{$\begin{array}{c}\mathrm{D} \\
\text { Mean (g) }\end{array}$} & \multirow{2}{*}{$\begin{array}{c}\mathrm{J} \\
\text { Mean (g) }\end{array}$} & \multicolumn{2}{|c|}{$\mathrm{F}_{1}$} & \multicolumn{2}{|c|}{ (D) $\mathrm{BC}_{1} \mathrm{~S}_{1}$ families } & \multicolumn{2}{|c|}{ (J) $\mathrm{BC}_{1} \mathrm{~S}_{1}$ families } \\
\hline & & & & Mean $(\mathrm{g})$ & Heterosis $^{\mathrm{y}}(\%)$ & Mean (g) & Range (g) & Mean (g) & Range (g) \\
\hline \multirow[t]{3}{*}{ FW1 } & 2002 Fall & 1.37 & 1.09 & 1.60 & 30 & 1.31 & $1.03-1.67 * * x$ & 1.32 & $1.00-1.84^{* * x}$ \\
\hline & 2003 Spring & 1.94 & 1.89 & 2.56 & 34 & 2.18 & $1.60-2.73 * *$ & 1.88 & $1.21-2.49 * *$ \\
\hline & 2004 Spring & 1.37 & 1.23 & 2.16 & 66 & 1.60 & $1.38-1.99 * *$ & 1.44 & $1.04-1.88 * *$ \\
\hline \multirow[t]{3}{*}{ FW2 } & 2002 Fall & 1.91 & 1.69 & 2.72 & 51 & 1.96 & $1.42-2.60 * *$ & 2.03 & $1.56-2.78 * *$ \\
\hline & 2003 Spring & 4.22 & 4.02 & 7.37 & 79 & 4.82 & $3.70-6.22 * *$ & 3.86 & $2.59-5.12 * *$ \\
\hline & 2004 Spring & 3.01 & 2.27 & 6.03 & 128 & 3.79 & $2.75-4.67 * *$ & 3.10 & $2.32-4.59 * *$ \\
\hline
\end{tabular}

${ }^{\mathrm{z}} \mathrm{FW} 1$, Fresh weight at transplanting stage; FW2, Fresh weight at 5 weeks after transplanting.

${ }^{y}$ Heterosis over the mid-parent $(\%)=100 \times\left(\mathrm{F}_{1}\right.$ value - mid-parent value $) /$ mid-parent value.

$x * *$ : Significant at the $1 \%$ level among families.

most cases higher than mid-parental values, and indicated heterosis; therefore, the backcrossed populations are thought to be useful for the study of heterosis.

\section{Map construction}

We newly added 25 co-dominant markers, 24 SSRs and 1 cleaved amplified polymorphic sequence (CAPS), to the previously reported AFLP-based maps (Fig. 1) (Ohara et al., 2005a). The J map covered $1,068 \mathrm{cM}$ with 16 linkage groups (J1-J16), and D map 1,104 cM with 15 linkage groups (D1-D15). Based on the map position of anchor markers, 15 pairs of linkage groups were detected. Twelve had 2 or more anchor markers (Fig. 1).

\section{QTL for seedling growth}

The detected QTLs are presented in Table 2 and Figure 1. Phenotypic variation explained by a single QTL was less than $24.7 \%$ and was not so high. Alleles that increased the fresh weight of seedlings were detected not only on the better parent $\mathrm{D}$, but also on the inferior parent J. Among the detected QTLs, those on D3 around AFS012, J5, and J9 were detected in more than 2 cultivations, and were inferred to be constantly effective. Only one pair of QTLs was found in the corresponding regions in J5 and D5. The other QTLs were found in either of the maps (Table 2).

\section{Estimation of genetic effects by comparison of the 2 maps}

Logically, the overdominance phenomenon cannot be detected in a single backcrossed map; therefore, here we estimate the overdominance effect on the genomic region where the QTL is detected on either of the maps (Table 3). For example, a QTL was detected near AFS012 on linkage group D3, but the LOD score of the corresponding genomic region of $\mathrm{J}$ map was lower than the threshold value. However, we used the analyzed data, $(d / 2)-a$ and $a+(d / 2)$ on the corresponding region obtained using QTL analysis. Using data of the 2 maps, we estimated the degree of dominance, $|d / a|$ in this genomic region. The figure of this region was 3.5 for FW1 and higher than the unit, indicating an overdominant effect in this region (Table 3). Most regions showing QTLs had a degree of dominance over the unit, and indicated complete dominance to overdominance.

One pair of QTLs was detected in corresponding regions in J5 and D5 (Table 3). These loci were considered an identical QTL; the degree of dominance of the QTL was estimated as 0.5. Similarly, at the QTLs on linkage groups 5 and 7 , the degree of dominance was estimated as low and was 0.5 or less. These loci were considered to be no dominant (additive) to partial dominant.

\section{Discussion}

\section{QTLs for seedling growth}

Vigorous growth in the young seedling stage is an important trait for adaptation of the seedling to undesirable growing conditions or competition with weeds; therefore, QTL analysis for seedling traits was conducted in some major crops. QTLs for plant height or traits relating to seedling growth were identified using recombinant inbred lines in wheat (Spielmeyer et al., 2007) and DH lines in maize (Presterl et al., 2007). The QTLs for seedling weight and length of rice were detected using $\mathrm{F}_{2}$ or $\mathrm{BC}_{1}$ populations of japonica $\times$ indica (Abdelkhalik et al., 2005; Redona and Mackill, 1996). In the present study, we identified many QTLs related to the seedling weight of bunching onion. The percentage of phenotypic variation explained by each QTL was not marked. Three QTLs on D3 around AFS012, J5, and J9 are considered to be consistently effective across different environmental conditions because they were detected in different years and seasons. These QTLs are expected to be targets of marker-aided selection (MAS) for rapid seedling growth. We previously reported a cluster of distorted markers showing an excess of heterozygotes near AFS012 on D3, and speculated about the presence of loci related to heterosis or inbreeding depression (Ohara et al., 2005a). This speculation was strongly supported by the detection of a highly effective QTL in the proximity of AFS012 on D3 in the present study. This QTL is thought to be constantly effective on seedling growth in the present population, showing clear 

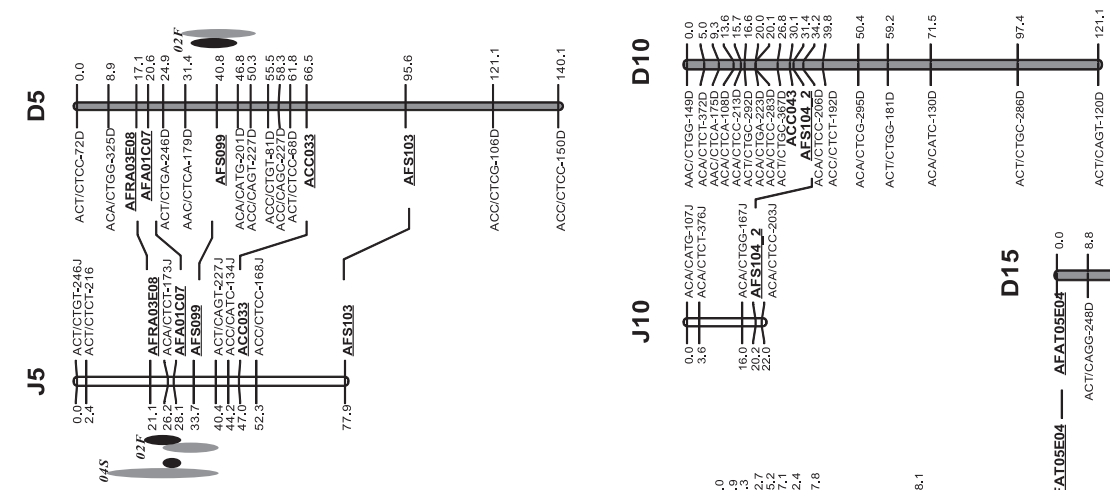

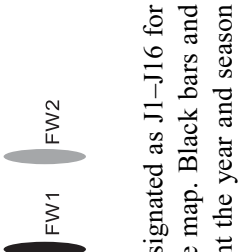
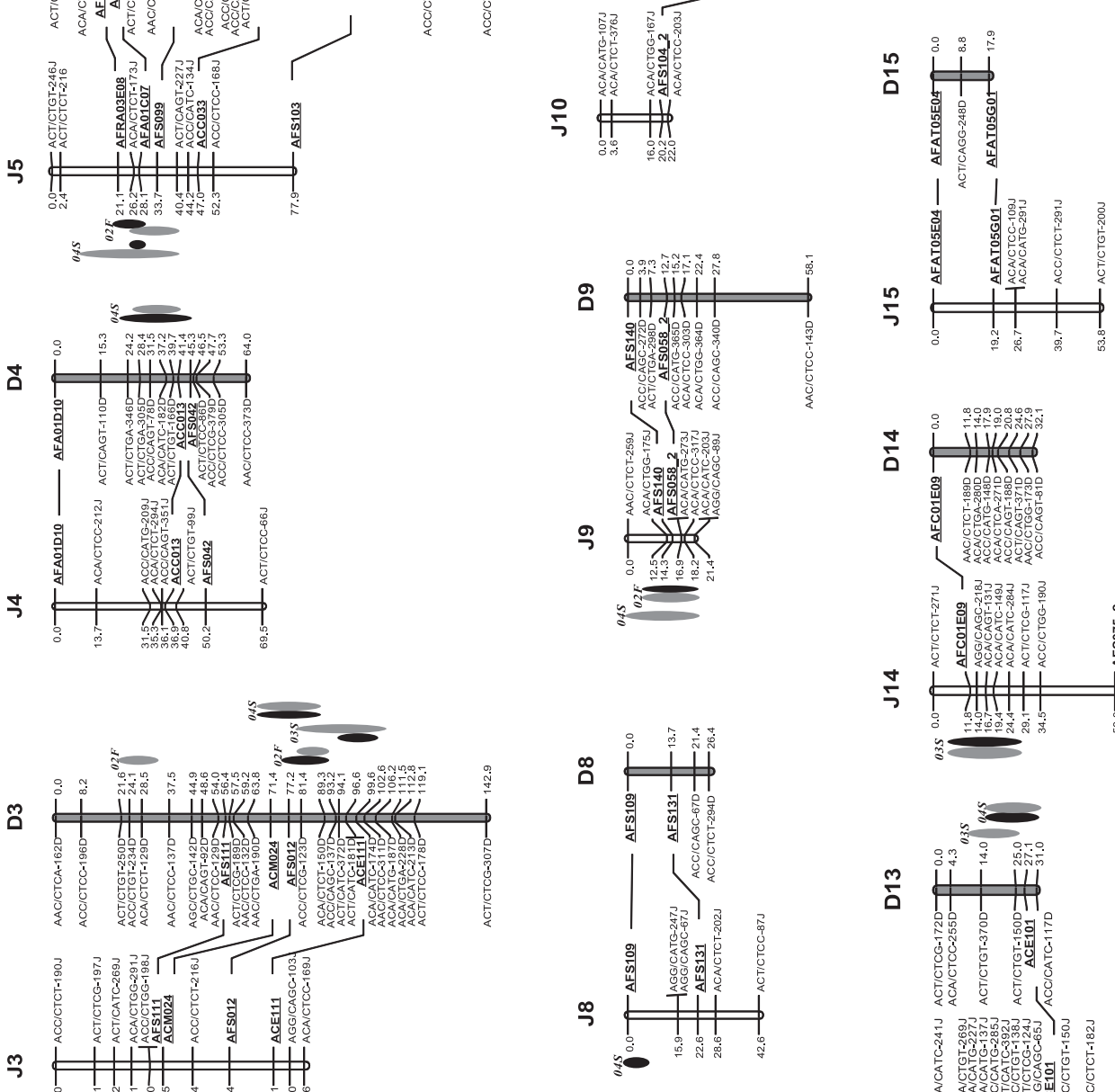

桊

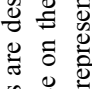

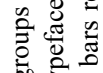

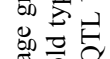

政

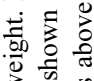

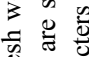

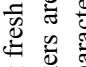

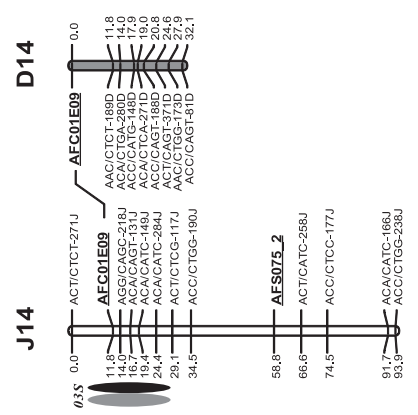

on

o

힝ํㅇ

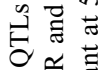

웅

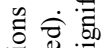

羟

웡

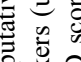

흘

ज家을

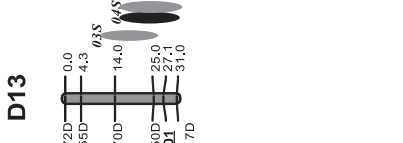

管.

蓄.

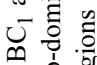

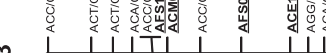

$m \underset{2}{2}$

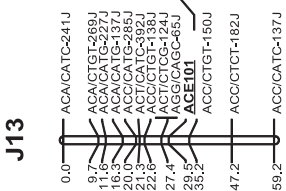

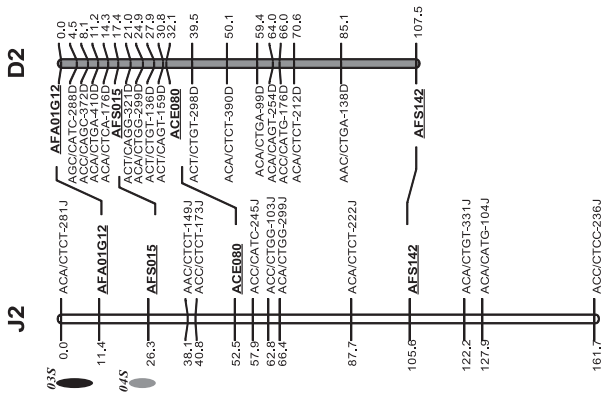

ลิ
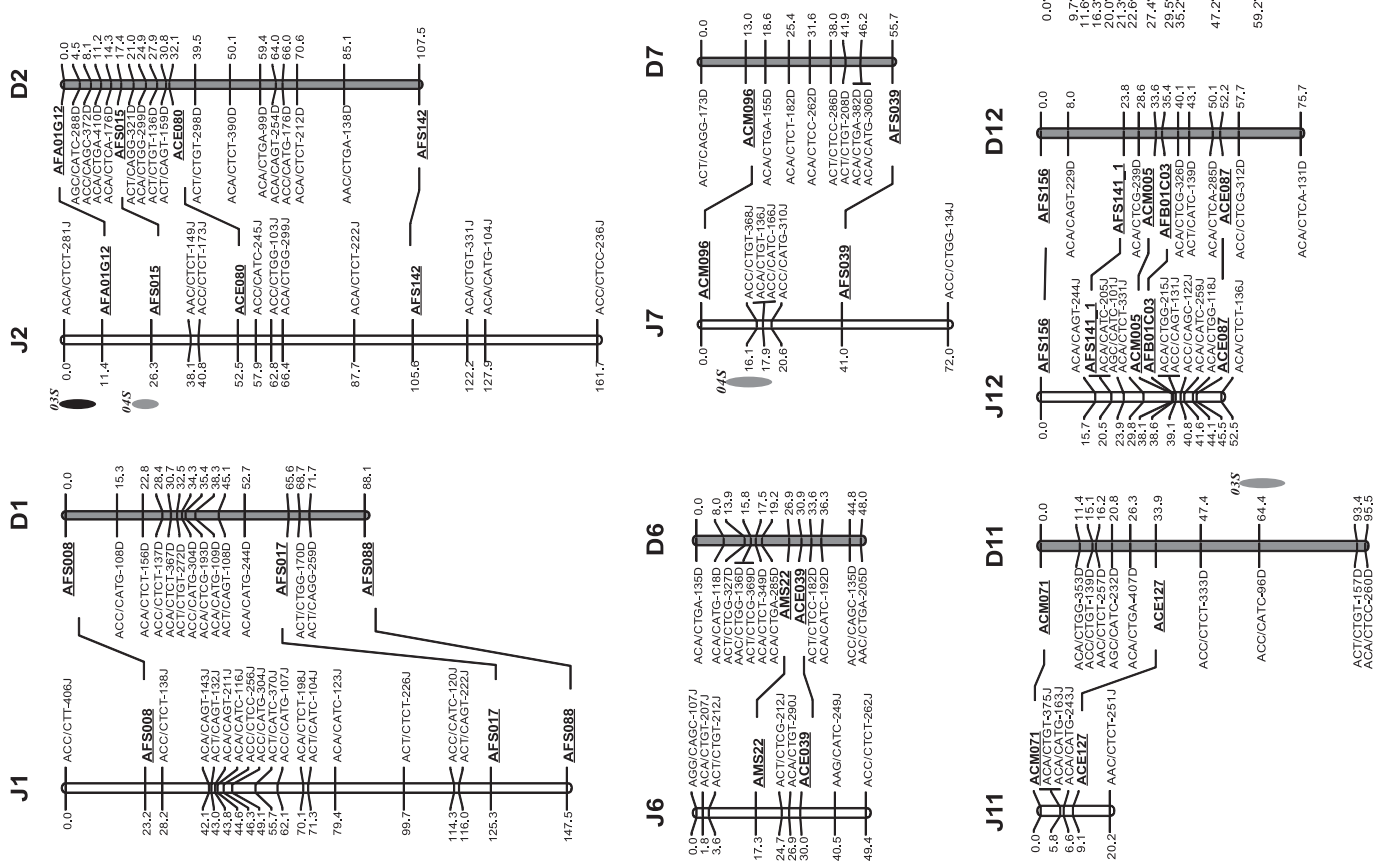

อ 
Table 2. QTLs for seedling weight detected on both $\mathrm{BC}_{1}$ maps.

\begin{tabular}{|c|c|c|c|c|c|c|c|}
\hline \multirow[b]{2}{*}{ Trait } & & \multicolumn{6}{|c|}{$\mathrm{J}$ map based on (D) $\mathrm{BC}_{1}$ population } \\
\hline & & $\begin{array}{l}\text { Linkage } \\
\text { group }\end{array}$ & Marker interval & Threshold $^{z}$ & LOD & $\begin{array}{l}\text { Genetic effect } \\
((d / 2)-a)\end{array}$ & $\operatorname{PVE}(\%)^{\mathrm{y}}$ \\
\hline \multirow[t]{7}{*}{ FW1 } & 2002 Fall & $\mathrm{J} 3$ & ACC/CTCT-190J-ACT/CTCG-197J & \multirow{3}{*}{2.6} & 3.3 & -0.09 & 13.5 \\
\hline & & J5 & AFRA03E08-ACA/CTCT-173J & & 2.9 & 0.05 & 6.7 \\
\hline & & J9 & ACA/CTCC-317J-ACA/CATC-203J & & 6.4 & 0.07 & 16.0 \\
\hline & \multirow[t]{2}{*}{2003 Spring } & $\mathrm{J} 2$ & ACA/CTCT-281J-AFA01G12 & \multirow{2}{*}{2.6} & 5.3 & 0.17 & 14.6 \\
\hline & & $\mathrm{J} 14$ & ACA/CATC-149J-ACA/CATC-284J & & 6.3 & 0.17 & 15.9 \\
\hline & \multirow[t]{2}{*}{2004 Spring } & $\mathrm{J} 5$ & AFRA03E08-ACA/CTCT-173J & \multirow{2}{*}{2.5} & 2.6 & 0.06 & 6.7 \\
\hline & & J8 & AFS109-AGG/CATG-247J & & 3.6 & 0.08 & 9.5 \\
\hline \multirow[t]{7}{*}{ FW2 } & \multirow[t]{2}{*}{2002 Fall } & $\mathrm{J} 5$ & ACA/CTCT-173J-AFA01C07 & \multirow{2}{*}{2.7} & 2.9 & 0.11 & 7.5 \\
\hline & & J9 & ACA/CTCC-317J-ACA/CATC-203J & & 5.2 & 0.15 & 14.7 \\
\hline & 2003 Spring & $\mathrm{J} 14$ & ACA/CATC-149J-ACA/CATC-284J & 2.7 & 4.3 & 0.33 & 11.5 \\
\hline & \multirow[t]{4}{*}{2004 Spring } & $\mathrm{J} 2$ & AFS015-AAC/CTCT-149J & \multirow{4}{*}{2.7} & 3.0 & 0.19 & 6.7 \\
\hline & & J5 & ACA/CTCT-173J-AFA01C07 & & 5.1 & 0.24 & 11.8 \\
\hline & & $\mathrm{J} 7$ & ACM096-ACC/CTGT-368J & & 3.3 & -0.20 & 7.8 \\
\hline & & J9 & ACA/CTCC-317J-ACA/CATC-203J & & 4.9 & 0.24 & 11.3 \\
\hline \multirow[b]{2}{*}{ Trait } & & \multicolumn{6}{|c|}{ D map based on $(J) B_{1}$ population } \\
\hline & & $\begin{array}{l}\text { Linkage } \\
\text { group }\end{array}$ & Marker interval & Threshold $^{z}$ & LOD & $\begin{array}{l}\text { Genetic effect } \\
(a+(d / 2))\end{array}$ & $\operatorname{PVE}(\%)^{\mathrm{y}}$ \\
\hline \multirow[t]{7}{*}{ FW1 } & \multirow[t]{2}{*}{2002 Fall } & D3 & AFS012-ACM024 & \multirow{2}{*}{2.7} & 3.3 & 0.16 & 9.7 \\
\hline & & D5 & AFS099-ACA/CATG-201D & & 3.3 & -0.07 & 8.7 \\
\hline & \multirow[t]{2}{*}{2003 Spring } & D3 & ACA/CATG-187D-AAC/CTCC-311D & \multirow{2}{*}{2.5} & 3.3 & 0.12 & 9.8 \\
\hline & & D13 & AAC/CTGA-190D-ACT/CTGT-150D & & 3.3 & 0.12 & 10.0 \\
\hline & \multirow[t]{3}{*}{2004 Spring } & D3 & AFS012-ACM024 & \multirow{3}{*}{2.6} & 7.8 & 0.13 & 24.4 \\
\hline & & D4 & ACC/CAGT-78D-ACA/CATC-182D & & 3.5 & 0.08 & 8.5 \\
\hline & & D13 & ACT/CTGT-370D-ACT/CTGT-150D & & 4.3 & 0.10 & 13.9 \\
\hline \multirow[t]{8}{*}{ FW2 } & \multirow[t]{3}{*}{2002 Fall } & D3 & ACA/CTCT-150D-ACC/CTCG-123D & \multirow{3}{*}{2.7} & 7.1 & 0.34 & 17.2 \\
\hline & & D3 & ACA/CTCT-129D-ACC/CTGT-234D & & 6.0 & -0.36 & 14.9 \\
\hline & & D5 & AAC/CTCA-179D-AFS099 & & 5.0 & -0.18 & 11.3 \\
\hline & \multirow[t]{2}{*}{2003 Spring } & D3 & ACA/CATG-187D-AAC/CTCC-311D & \multirow{2}{*}{2.6} & 4.1 & 0.37 & 12.3 \\
\hline & & D11 & ACC/CTCT-333D-ACC/CATC-96D & & 3.0 & -0.33 & 10.0 \\
\hline & \multirow[t]{3}{*}{2004 Spring } & D3 & AFS012-ACM024 & \multirow{3}{*}{2.6} & 9.4 & 0.42 & 24.7 \\
\hline & & D4 & ACT/CTGA-305D-ACC/CAGT-78D & & 3.8 & 0.25 & 8.8 \\
\hline & & D13 & ACE101-ACC/CATC-117D & & 5.2 & 0.31 & 13.2 \\
\hline
\end{tabular}

${ }^{\mathrm{z}}$ LOD threshold given by 1,000 permutation test at $P<0.05$.

${ }^{y}$ Phenotypic variation explained by the QTL.

overdominance, as discussed below. Recently, Tsukazaki et al. (2008) constructed an SSR-based bunching onion map and assigned the linkage groups to chromosomes of bunching onion and/or bulb onion (Allium cepa L.) using alien monosomic addition lines developed by Shigyo et al. (1996). It is suggested that the linkage group D3 corresponds to linkage group 2a on the SSR-based map, which is assigned to A. cepa chromosome 2 (Tsukazaki et al., 2008).

\section{Genetic nature of heterosis}

Heterosis has usually been explained by 2 major hypotheses: the dominance hypothesis (Davenport, 1908; Keeble and Pellew, 1910) and the overdominance hypothesis (East, 1936), but the genetic basis of heterosis has been insufficiently understood to date. Stuber et al. (1992) reported that heterozygotes at almost all QTLs for the yield of maize had a higher phenotype than the respective homozygotes, and suggested that overdominance or pseudo-overdominance played a role in this heterosis. In contrast, Xiao et al. (1995) reported that complementation of dominant genes, including partial dominant alleles at different loci, was the major genetic basis of heterosis in rice. Meanwhile, overdominance resulting from epistasis was reported as strongly related with heterosis in rice (Hua et al., 2003; Mei et al., 2005).

Hayman (1954) presented a concept regarding the limit of selection. This limit is the maximum phenotypic value of an ideal pure line in which all the better alleles were homozygously accumulated. This limit is calcula- 
Table 3. Genetic effect at each QTL estimated by the comparison of corresponding map regions.

\begin{tabular}{|c|c|c|c|c|c|c|c|c|c|c|}
\hline \multirow[b]{2}{*}{ Trait } & & \multicolumn{3}{|c|}{$\mathrm{J}$ map based on (D) $\mathrm{BC}_{1}$} & \multicolumn{3}{|c|}{$\mathrm{D}$ map based on $(\mathrm{J}) \mathrm{BC}_{1}$} & \multicolumn{3}{|c|}{ Estimates of genetic effects ${ }^{\mathrm{z}}$} \\
\hline & & $\begin{array}{l}\text { Linkage } \\
\text { group }\end{array}$ & Nearest marker & $(d / 2)-a$ & $\begin{array}{l}\text { Linkage } \\
\text { group }\end{array}$ & Nearest marker & $a+(d / 2)$ & $a$ & $d$ & $|d / a|$ \\
\hline FW1 & 03 Spring & $\underline{J 2}$ & $\underline{A C A / C T C T-281 J}$ & $\underline{0.17}$ & $\mathrm{D} 2$ & AFA01G12 & 0.03 & -0.07 & 0.20 & 2.9 \\
\hline FW2 & 04 Spring & $\underline{J 2}$ & $\underline{A F S 015}$ & $\underline{0.19}$ & D2 & ACT/CAGG-321D & -0.02 & -0.11 & 0.17 & 1.6 \\
\hline FW1 & 02 Fall & $\mathrm{J} 3$ & АCC/СТCT-216J & 0.04 & $\underline{D 3}$ & $\underline{A F S 012}$ & $\underline{0.16}$ & 0.06 & 0.20 & 3.5 \\
\hline FW1 & 04 Spring & $\mathrm{J} 3$ & ACC/CTCT-216J & 0.02 & $\underline{D 3}$ & $\underline{A F S 012}$ & $\underline{0.13}$ & 0.06 & 0.15 & 2.8 \\
\hline FW2 & 02 Fall & $\mathrm{J} 3$ & AFS012 & -0.04 & $\underline{D 3}$ & $\underline{A C A / C T C T-150 D}$ & $\underline{0.34}$ & 0.19 & 0.31 & 1.6 \\
\hline FW2 & 03 Spring & $\mathrm{J} 3$ & ACE111 & -0.08 & $\underline{D 3}$ & $\underline{A C A / C A T G-187 D}$ & $\underline{0.37}$ & 0.23 & 0.29 & 1.3 \\
\hline FW2 & 04 Spring & $\mathrm{J} 3$ & AFS012 & 0.01 & $\underline{D 3}$ & $\underline{A F S 012}$ & $\underline{0.42}$ & 0.21 & 0.43 & 2.1 \\
\hline FW1 & 04 Spring & $\mathrm{J} 4$ & ACA/CTCT-294J & 0.02 & $\underline{D 4}$ & $\underline{A C C / C A G T-78 D}$ & $\underline{0.08}$ & 0.03 & 0.10 & 3.5 \\
\hline FW2 & 04 Spring & $\mathrm{J} 4$ & ACA/CTCC-212J & 0.09 & $\underline{D 4}$ & $\underline{A C T / C T G A-305 D}$ & $\underline{0.25}$ & 0.08 & 0.34 & 4.4 \\
\hline FW1 & 02 Fall & $\mathrm{J} 5$ & AFS099 & 0.05 & $\underline{D 5}$ & $\underline{A F S 099}$ & -0.07 & -0.06 & -0.03 & 0.5 \\
\hline FW2 & 02 Fall & $\underline{J 5}$ & $\underline{A C A / C T C T-173 \mathrm{~J}}$ & $\underline{0.11}$ & $\underline{D 5}$ & $\underline{A F S 099}$ & -0.18 & -0.14 & -0.07 & 0.5 \\
\hline FW2 & 04 Spring & $\underline{J 5}$ & $\underline{A C A / C T C T-173 \mathrm{~J}}$ & $\underline{0.24}$ & D5 & AFS099 & -0.14 & -0.19 & 0.10 & 0.5 \\
\hline FW2 & 04 Spring & $\underline{J 7}$ & $\underline{A C C / C T G T-368 J}$ & $\underline{-0.20}$ & D7 & ACA/CTGA-155D & 0.17 & 0.19 & -0.02 & 0.1 \\
\hline FW1 & 04 Spring & $\underline{J 8}$ & $\underline{A F S 109}$ & $\underline{0.08}$ & D8 & AFS109 & -0.01 & -0.04 & 0.06 & 1.4 \\
\hline FW1 & 02 Fall & $\underline{J 9}$ & $\underline{A C A / C T C C-317 J}$ & $\underline{0.07}$ & D9 & AFS 140 & -0.03 & -0.05 & 0.04 & 0.9 \\
\hline FW2 & 02 Fall & $\underline{J 9}$ & $\underline{A C A / C T C C-317 J}$ & $\underline{0.15}$ & D9 & ACA/CTCC-364D & 0.04 & -0.06 & 0.19 & 3.4 \\
\hline FW2 & 04 Spring & $\underline{J 9}$ & $\underline{A C A / C T C C-317 J}$ & $\underline{0.24}$ & D9 & ACA/CTGG-364D & 0.09 & -0.07 & 0.34 & 4.6 \\
\hline FW1 & 04 Spring & $\mathrm{J} 13$ & ACE101 & 0.01 & $\underline{D 13}$ & $\underline{A C T / C T G T-150 D}$ & $\underline{0.10}$ & 0.05 & 0.10 & 2.2 \\
\hline FW2 & 04 Spring & $\mathrm{J} 13$ & ACE101 & 0.02 & $\overline{D 13}$ & $\underline{A C C / C A T C-117 D}$ & $\overline{0.31}$ & 0.14 & 0.33 & 2.3 \\
\hline FW1 & 03 Spring & $\underline{J 14}$ & $\underline{A C A / C A T C-149 \mathrm{~J}}$ & $\underline{0.17}$ & D14 & AFC01E09 & 0.04 & -0.06 & 0.21 & 3.2 \\
\hline FW2 & 03 Spring & $\underline{J 14}$ & $\underline{A C A / C A T C-149 \mathrm{~J}}$ & $\underline{0.33}$ & D14 & AFC01E09 & 0.28 & -0.03 & 0.62 & 23.6 \\
\hline
\end{tabular}

${ }^{\mathrm{z}} a$, additive effect; $d$, dominant effect.

Significant QTLs detected in composite interval mapping (CIM) are indicated in italics with underlining.

The others were not significant in CIM.

ble in diallel analysis (Christie and Shattuck, 1992). Theoretically, the limits cannot be exceeded without overdominance. We previously reported evidence that many $F_{1}$ had a seedling weight that was higher than the selection limits in diallel analysis in bunching onion (Ohara et al., 2004). The evidence strongly suggests that overdominance plays a major role in this heterosis. Furthermore, the results of diallel analysis showed that epistasis was not conspicuous in seedling weights (Ohara et al., 2004). Consequently, we discussed only the single locus effect and did not consider epistasis in this report.

We first speculated that QTLs should be detected in 2 corresponding regions of both maps if overdominance plays a major role in heterosis; however, we were unable to obtain such clear evidence of overdominance in composite interval mapping in this study. It was considered that detection of significant differences between heterozygotes and the better homozygotes was not easy when the level of overdominance was not high. This is partly because this study was conducted using the $\mathrm{BC}_{1} \mathrm{~S}_{1}$ generation, where the dominance effect theoretically decreases to half that of the $\mathrm{BC}_{1}$ generation.
Nevertheless, most QTLs showed the estimated degree of dominance over the unit and were suggested to be overdominant. However, the present results did not indicate that the detected overdominance phenomenon originated from a single gene showing overdominance. The effect of 2 tightly linked loci, designated as pseudooverdominance, cannot be ruled out (Jones, 1917). More detailed analysis of each QTL is necessary to clarify this issue.

In conclusion, the seedling weight in bunching onion in the initial growth stage is considered to be controlled by many QTLs that exhibit various modes of gene actions, additive, dominant, and overdominant. The results suggest that remarkable heterosis in the trait is based on the accumulation of dominant and overdominant (or pseudo-overdominant) alleles. The present results might offer one strategy on MAS for an $\mathrm{F}_{1}$ cultivar of bunching onion having excellent seedling growth. The targets should be 3 QTLs on D3 around AFS012, J5, and $\mathrm{J}$, which showed stable effects on seedling growth. The QTLs on D3 and J9 exhibit overdominant gene actions; therefore, it is necessary to maintain heterozy- 
gosity at these loci in the $\mathrm{F}_{1}$ hybrid. The homozygosity of the $\mathrm{J}$ allele is sufficient for the QTL on J5 because of its additive to partial dominant gene action. Because phenotypic variation explained by the above 3 loci was not too large, conventional selection is expected to be necessary for MAS-derived seedlings.

\section{Acknowledgements}

We are deeply grateful to Dr. M. Hirai, Graduate School of Life and Environmental Science, Kyoto Prefectural University, Japan for critical reading of the manuscript and helpful advice.

\section{Literature Cited}

Abdelkhalik, A. F., R. Shishido, K. Nomura and H. Ikehashi. 2005. QTL-based analysis of heterosis for grain shape traits and seedling characteristics in an indica-japonica hybrid in rice (Oryza sativa L.). Breed. Sci. 55: 41-48.

Christie, B. R. and V. I. Shattuck. 1992. The diallel cross: Design, analysis, and use for plant breeders. Plant Breed. Rev. 9: 9-36.

Davenport, C. B. 1908. Degeneration, albinism and inbreeding. Science 28: 454-455.

East, E. M. 1936. Heterosis. Genetics 21: 375-397.

Hayman, B. I. 1954. The theory and analysis of diallel crosses. Genetics 39: 789-809.

Hua, J. P., Y. Z. Xing, W. Wu, C. Xu, X. Sun, S. Yu and Q. Zhang. 2003. Single-locus heterotic effects and dominance by dominance interactions can adequately explain the genetic basis of heterosis in an elite rice hybrid. Proc. Natl. Acad. Sci. 100: 2574-2579.

Inden, H. and T. Asahira. 1990. Japanese bunching onion (Allium fistulosum L.). p. 159-178. In: H. D. Rabinowitch and J. L. Brewster (eds.). Onions and Allied Crops. Vol. III. Biochemistry, Food Science, and Minor Crops. CRC, Boca Raton, FL.

Jones, D. F. 1917. Dominance of linked factors as a means of accounting for heterosis. Genetics 2: 466-479.

Keeble, F. and C. Pellew. 1910. The mode of inheritance of stature and flowering time in peas (Pisum sativam). J. Genet. 1: 4756.

Kosambi, D. 1944. The estimation of map distance from recombination values. Ann. Eugen. 12: 172-175.

Lander, E., P. Green, J. Abrahamson, A. Barlow, M. Daly, S. Lincoln and L. Newburg. 1987. MAPMAKER: An interactive computer package for constructing primary genetic linkage maps of experimental and natural populations. Genomics 1: 174-181.

Lu, H., J. Romero-Severson and R. Bernardo. 2003. Genetic basis of heterosis explored by simple sequence repeat markers in a random-mated maize population. Theor. Appl. Genet. 107: 494-502.

MAFF. Japan. 2008. Seisan nougyou shotoku toukei (2006). http: //www.tdb.maff.go.jp/toukei/toukei. June 23, 2009.

Mei, H. W., Z. K. Li, Q. Y. Shu, L. B. Guo, Y. P. Wang, X. Q. Yu, C. S. Ying and L. J. Luo. 2005. Gene actions of QTLs affecting several agronomic traits resolved in a recombinant inbred rice population and two backcross populations. Theor. Appl. Genet. 110: 649-659.

Ohara, T., T. Wako and A. Kojima. 2004. Diallel analysis of seedling growth in Japanese bunching onion (Allium fistulosum L.). Breed. Res. 6: 11-19 (In Japanese with English abstract).
Ohara, T., Y. S. Song, H. Tsukazaki, T. Wako, T. Nunome and A. Kojima. 2005a. Genetic mapping of AFLP markers in Japanese bunching onion (Allium fistulosum). Euphytica 144: 255-263.

Ohara, T., T. Wako, T. Nunome and A. Kojima. 2005b. Relationship between heterosis and genetic distances as revealed by AFLP markers in intervarietal $F_{1}$ hybrids of Japanese bunching onion (Allium fistulosum). J. Japan. Soc. Hort. Sci. 74: 68-77 (In Japanese with English abstract).

Presterl, T., M. Ouzunova, W. Schmidt, E. M. Möller, F. K. Röber, C. Knaak, K. Ernst, P. Westhoff and H. H. Geiger. 2007. Quantitative trait loci for early plant vigour of maize grown in chilly environments. Theor. Appl. Genet. 114: 1059-1070.

Redona, E. D. and D. J. Mackill. 1996. Mapping quantitative trait loci for seedling vigor in rice using RFLPs. Theor. Appl. Genet. 92: 395-402.

Ricroch, A., R. Yockteng, S. C. Brown and S. Nadot. 2005. Evaluation of genome size across some cultivated Allium species. Genome 48: 511-520.

Shigyo, M., Y. Tashiro, S. Isshiki and S. Miyazaki. 1996. Establishment of a series of alien monosomic addition lines of Japanese bunching onion (Allium fistulosum L.) with extra chromosomes from shallot (A. cepa L. Aggregatum group). Genes Genet. Syst. 71: 363-371.

Shiraiwa, N., Y. Kashima, Y. Noguchi and H. Inoue. 2006. Development of the year-round system using a full-automatic transplanter with improvement of plug seedling nursery in welsh onion. Bull. Tottori Hort. Exp. Stn. 7: 19-28 (In Japanese).

Song, Y. S., K. Suwabe, T. Wako, T. Ohara, T. Nunome and A. Kojima. 2004. Development of microsatellite markers in bunching onion (Allium fistulosum L.). Breed. Sci. 54: 361365.

Spielmeyer, W., J. Hyles, P. Joaquim, F. Azanza, D. Bonnett, M. E. Ellis, C. Moore and R. A. Richards. 2007. A QTL on chromosome 6A in bread wheat (Triticum aestivum) is associated with longer coleoptiles, greater seedling vigour and final plant height. Theor. Appl. Genet. 115: 59-66.

Stuber, C. W., S. E. Lincoln, D. W. Wolff, T. Helentjaris and E. S. Lander. 1992. Identification of genetic factors contributing to heterosis in a hybrid from two elite maize inbred lines using molecular markers. Genetics 132: 823-839.

Tsukazaki, H., T. Nunome, H. Fukuoka, H. Kanamori, I. Kono, K. Yamashita, T. Wako and A. Kojima. 2007. Isolation of 1,796 SSR clones from SSR-enriched DNA libraries of bunching onion (Allium fistulosum). Euphytica 157: 83-94.

Tsukazaki, H., K. Yamashita, S. Yaguchi, S. Masuzaki, H. Fukuoka, J. Yonemaru, H. Kanamori, I. Kono, T. T. M. Hang, M. Shigyo, A. Kojima and T. Wako. 2008. Construction of SSR-based chromosome map in bunching onion (Allium fistulosum). Theor. Appl. Genet. 117: 1213-1223.

Wang, S., C. J. Basten and Z-B. Zeng. 2007. Windows QTL Cartographer 2.5. Department of Statistics, North Carolina State University, Raleigh, NC. http://statgen.ncsu.edu/qtlcart/ WQTLCart.htm. June 23, 2009.

Xiao, J., J. Li, L. Yuan and S. D. Tanksley. 1995. Dominance is the major genetic bases of heterosis in rice as revealed by QTL analysis using molecular markers. Genetics 140: 745754.

Yokoyama, M. 1996. Development of machine-assisted transplantation technique utilizing seedlings that are grown in a specially-arranged cell system. Bull. Shizuoka Agr. Exp. Stn. 41: 13-23 (In Japanese with English abstract). 